\title{
Investigating the expression pattern of the OsAPx1 gene promoter in rice
}

\author{
Julio Garighan*, Carolina Ribeiro, Márcia Margis-Pinheiro \\ From 5th Congress of the Brazilian Biotechnology Society (SBBIOTEC) \\ Florianópolis, Brazil. 10-14 November 2013
}

\begin{abstract}
Background
Ascorbate peroxidase (APx) is a key enzyme of the antioxidant metabolism, catalyzing the decomposition of hydrogen peroxide $\left(\mathrm{H}_{2} \mathrm{O}_{2}\right)$ in water, using ascorbate as an electron donor. The $\mathrm{H}_{2} \mathrm{O}_{2}$ is a reactive oxygen species (ROS) produced constantly by aerobic metabolism. Under biotic and abiotic stress the level of $\mathrm{H}_{2} \mathrm{O}_{2}$ increases and, in large quantities, can cause cellular damage. In rice, there are eight APx genes that encode products target to different subcellular compartments: cytosol, peroxisoma, mitochondria and chloroplast. OsAPx1 gene encodes a cytosolic isoform of APx. The study of promoters is an important tool that allows to analyze the overall expression pattern of genes in plants.
\end{abstract}

\section{Methods}

A sequence of approximately $2 \mathrm{~kb}$ preceding the translation initiation site of the OSAPX1 gene was isolated, cloned into pENTR vector and recombined in PHGWFS7 vector, whichallows the fusion of the promoter sequence with two report genes, Gfp and Gus, and confers resistence to hygromycin. The construction was named pPROM1. The transformation of rice calli, originated from nipponbare cultivar seeds, was performed via Agrobacterium tumefaciens. The transformed calli were grown in selection medium with hygromycin, regenerated into plants, acclimatized in a greenhouse and the confirmation of transgene was verified by PCR using specific primers for the $\mathrm{Hpt}$ and Gus genes. For visualization of expression pattern of the promoter, by GUS histochemical assay, samples of plants were collected and analyzed by $X$-gluc histochemical assays. The segments were incubated in $1 \mathrm{mMX}$-gluc solution at $37^{\circ} \mathrm{C}$ for $16 \mathrm{~h}$. After reaction, green tissues were incubated in $70 \%$ ethanol for chlorophyll discoloration. In the in silico analysis of cis-elements in the promoter region of $O s A P x 1$ was used the following databases available online:-PlantPan (plantpan.mbc.nctu.edu.tw/) and PlantCare (http://bioinformatics.psb.ugent.be/webtools/plantcare/html/)

\section{Results and conclusions}

Nine lines of transgenic plants expressing Gus under the control of the OSAPX1 promoter were obtained. The GUSexpression was observed in leaf (especially in leaf mesophyll), ligule and in wounded regions. These results show that OsAPx1 gene seems to be expressed in green tissues and to respond to damage. Apparently, there is no change in the expression pattern during different development stages. The in silico analysis demonstrates the presence cis-elements responsive to hormones, drought and light.

\section{Acknowledgements}

CNPq, FAPERGS, CAPES and ICGEB.

Published: 1 October 2014

\section{References}

1. Jefferson RA, Kavanagh TA, Bevan MW: GUS fusions: beta-glucuronidase as a sensitive and versatile gene fusion marker in higher plants. $E M B O \mathrm{~J}$ 1987, 6(13):3901-3907.

2. Upadhyaya NM, Surin B, Ramm K, Gaudron J, Schünmann PHD, Taylor W, Waterhouse PM, Wang MB: Agrobacterium-mediated transformation of Australian rice cultivars Jarrah and Amaroo using modified promoters and selectable markers. Australian Journal Plant Physiology 2000, 27(3):201-210.

3. Teixeira FK, Menezes-Benavente L, Margis R, Margis-Pinheiro M: Analysis of the molecular evolutionary history of the ascorbate peroxidase gene family: inferences from the rice genome. J Mol Evol 2004, 59(6):761-770.

\section{doi:10.1186/1753-6561-8-S4-P92}

Cite this article as: Garighan et al:: Investigating the expression pattern of the OsAPx1 gene promoter in rice. BMC Proceedings 2014 8(Suppl 4):P92. 